\title{
PREPARANDO O DESPERTAR DE LILITH: A ENFERMAGEM NO FEMININO RETRATADA PELAS PUBLICAÇÕES DA REBEn DURANTE AS DÉCADAS DE OITENTA E NOVENTA DO SÉCULOXX
}

\author{
PREPARING THE AWAKENING OF LILITH: GENDER IN NURSING IN THE ARTICLES OF REBEn \\ (BRAZILIAN JOURNAL OF NURSING) DURING THE 1980`S AND 1990`S
}
PREPARANDO EL DESPERTAR DE LILITH: LAENFERMERÍA EN LO FEMENINO RETRATADA POR LAS PUBLICACIONES DE LA REBEn DURANTE LOS AÑOS OCHENTA Y NOVENTA DEL SIGLOXX

Lucia Helena Rodrigues Costa ${ }^{1}$

\begin{abstract}
RESUMO: Este estudo apresenta um levantamento das publicações da Revista Brasileira de Enfermagem/REBEn durante as décadas de 80 e 90 do século XX relativas especificamente 'as condições da mulher e/ou mulher/enfermeira. Inicialmente pensei em levantar apenas os artigos que apresentassem alguma referência à gênero, mas percebi que desde o inicio dos anos oitenta alguns artigos já apontavam na direção da problemática que envolve as mulheres socialmente e as implicações dessa problemática para o exercício da enfermagem, sem no entanto utilizar especificamente a categoria gênero. Assim, optei por uma avaliação dos resumos e conteúdos dos artigos no sentido de detectar todos aqueles pertinentes à essa área de interesse. Foram selecionados 11 artigos e dois editoriais temáticos que inserem a REBEn ( embora num primeiro momento pareça uma inserção tímida) efetivamente como revista contextualizada com os momentos decisivos do movimento das mulheres a nivel mundial.
\end{abstract}

PALAVRAS CHAVE: estudo das mulheres, gênero, história da Enfermagem, feminismo, REBEn

ABSTRACT: This study presents an analysis of the conditions of women/nurses in the articles published by REBEn (Brazilian Journal of Nursing) in the 1980's and 1990's. Initially, the researcher intended to analyze specifically those articles which had some reference to gender. However, in the beginnings of the 1980's, some articles pointed in the direction of the social problems involving women and the implication of these problems to nurses, without making explicit reference to gender category. Thus, the author decided to evaluate abstracts and the content of different articles, in order to detect those which were related to the subject of investigation. Eleven articles and two thematic editorials selected show that REBEn, although timidly, is a magazine which is updated regarding decisive moments of women's worldwide movement.

KEYWORDS: women studies, gender, history of nursing, feminism

RESUMEN: El estudio presenta un levantamiento de las publicaciones de la Revista Brasileira de Enfermagem/ReBEn durante los años 80 y 90 del siglo XX que se relacionan especificamente a las condiciones de la mujer y de la mujer/ enfermera. Inicialmente, pensé plantear apenas los artículos que presentasen alguna referencia al género, pero percibi que desde el principio de los años ochenta algunos artículos ya apuntaban hacia la problemática que involucra a las mujeres socialmente y las implicaciones de esa problemática para el ejercicio de la enfermeria, aunque no se utilice específicamente la categoría género. Así, opté por una evaluación de los resúmenes y contenidos de los artículos, en el sentido de detectar todos aquellos pertinentes a esa área de interés. Se seleccionaron 11 artículos y dos editoriales temáticos que insieren a REBEn (aunque en el primer momento parezca una inserción tímida)efectivamente, como una revista contextualizada/ comprometida con los momentos decisivos del movimiento de las mujeres a nivel mundial.

PALABRAS CLAVE: estudio de las mujeres, género, historia de la enfermeria, feminismo

Recebido em 31/08/2002

Aprovado em 27/09/2002

${ }^{1}$ Enfermeira. Docente do Curso de Graduação em Enfermagem da Universidade Estadual de Montes Claros/MGUNIMONTES. Coordenadora Pedagógica do Curso de Qualificação Profissional Auxiliar de Enfermagem/PROFAE/UNIMONTES/ FADENOR. Mestra em Enfermagem pela Universidade Federal de Santa Catarina/ UFSC. 


\section{CONTEXTUALIZANDO O DESPERTAR DE LILITH²}

A década de setenta do século $X X$ marcou profundamente a história recente das mulheres ocidentais, num momento que, dentre tantos outros movimentos importantes de cultura e contracultura, o Feminismo marca indelevelmente e podemos dizer até, demarca posições importantes nos avanços conseguidos pelas mulheres desde o final do século XIX. Grossi (s. d., p. 5) diz que:

O ano de 1968 é um marco simbólico para o surgimento do "novo feminismo" em vários países do mundo. No bojo das manifestações politicas deste momento , levadas a cabo sobretudo por jovens nascidos no pósguerra, surgem inúmeros grupos de mulheres que lutam por sua libertação, grupos que se auto-denominarão feministas, articulando seu ideário comas lutas políticas das mulheres do final do século XIX.

O Feminismo vai surgir no Brasil também nos anos setenta em plena ditadura militar, com o primeiro encontro realizado no Rio de Janeiro em 1975, Ano Internacional da Mulher. Vários grupos de mulheres surgiram nessa época, que culminou com sua progressiva institucionalização nos anos 80 . Essa é uma década em que surgem as primeiras delegacias da mulher e a criação de Conselhos de Direitos da Mulher. Na área de saúde o grande marco relacionado à saúde da mulher a partir de um "novo olhar" foi a criação do Programa de Atendimento Integral à Saúde da Mulher ( PAISM). Também nessa década se intensificam nas universidades as pesquisas sobre as mulheres e gênero com o aparecimento de vários núcleos de pesquisa sobre o assunto. A Conferência de Nairóbi realizada em 1985 foi um marco também para o movimento feminista brasileiro pela participação efetiva nesse encontro, e de certa forma, uma amostra do que seria a Conferência realizada uma década depois em Pequim, na China, no ano de 1994.

Foi pensando em toda essa conjuntura relatada nesse brevíssimo histórico que foi realizado este trabalho. $O$ objetivo principal foi detectar como a Revista Brasileira de Enfermagem ( ReBEn) periódico nacional ligado historicamente à Associação Brasileira de Enfermagem (ABEn) desde os seus primórdios, retratou esse movimento uma vez que é a Enfermagem uma profissão de maioria feminina. Para alcançar tal objetivo delimitei as décadas de
80 e 90 e, inicialmente pensei em resgatar apenas artigos que tivessem alguma referência de gênero. Com a pesquisa em andamento resolvi ampliar a busca para questões relativas às mulheres, processo histórico da mulher, movimento feminista, enfim expressões que apontavam pistas de que embora não utilizassem gênero como categoria falavam da temática da condição da mulher de maneira mais abrangente, e que era necessário apreender.

Foram consultados os periódicos editados pela REBEn nesse periodo, existentes nas bibliotecas da Universidade Estadual de Montes Claros, Faculdades Pitágoras de Montes Claros e biblioteca universitária do campus da saúde da Universidade Federal de Minas Gerais. Apenas sete números da revista não foram encontrados nas referidas bibliotecas, e das demais consultadas, selecionei nove artigos e dois editoriais.

\section{A PREPARAÇÃO DO DESPERTAR DE LILITH}

O primeiro artigo (CASTRO; CARVALHO; BORGES, 1982) que faz referência ao status da mulher na sociedade como um fator importante da definição social do papel da enfermeira na equipe de saúde foi publicado em 1982. Tratase de um trabalho que foi apresentado em um congresso internacional de enfermeiras em Porto Rico no ano de 1979, em que as autoras apontam a necessidade de que as enfermeiras entendam, e porque não pratiquem a filosofia feminista, uma vez que o progresso da enfermagem tem ligação com o movimento feminista, em especial, por ser a enfermagem uma profissão marcadamente feminina o que trás muitas implicações para a prática profissional. Duas das autoras tinham, no momento em que escreveram o artigo um envolvimento com o ensino (docentes da UFRJ) e a outra, à época, havia ocupado um cargo como consultora da Organização Panamericana de Saúde.

Em 1983, outro artigo (CORADINI; BARBIANI, 1983) escrito por duas enfermeiras ligadas à assistência hospitalar, uma de Porto Alegre e a outra de Bento Gonçalves, trás a questão histórica feminina vinculada à prática de enfermagem de maneira "indignada", em muitas passagens apresentando características muito mais panfletárias que científicas. Embora o texto apresente algumas incorreções do ponto de vista histórico, trás uma grande contribuição no sentido de

\footnotetext{
${ }^{2}$ Utilizei a metáfora do despertar de Lilith a partir do significado do mito mencionado no Antigo Testamento, Livro dos Profetas, Isaias 34/14, poema apocaliptico: lá também descansará Lilith, achará um pouso para si em companhia dos gatos selvagens, das hienas, dos sátiros da vibora e dos abutres. "É da aproximação dessa passagem ( o exílio de Lilith) com os dois relatos da criação do homem e da mulher por Jeová ( capitulos I e II do Genesis ) que nasce o mito de Lilith nos tempos modernos: primeira mulher a ser criada, ela pronunciou o "nome inefável" que the deu as asas por meio das quais fugiu do jardim do Éden, onde abandonou Adão, com quem não se entendia. Ratificada pela perseguição de três anjos- Sinoi, Sinsinoi e Samengeloff, que, encontrando-a às margens do Mar Vermelho, em vão pediram-lhe que voltasse -, essa fuga converteu-se em expulsão. Desde esse dia, em resposta à ameaça proferida pelos três anjos ( ela veria milhares de seus filhos mortos diariamente), e por desejo de vingança e ciúmes para com Eva, criada depois dela para substituí-la_criada não mais do barro como Adão ou Lilith ( o que é apontado como sendo a causa do desentendimento entre Lilith e Adão), mas de uma costela desse último-Lilith retorna ao mundo dos homens, descendentes de Adão e Eva, para fazer-lhes mal. (...) a evolução desse mito ao correr dos textos, e suas ressurgências repetidas nos tempos modernos, tendem a atrair nossa atenção de maneira particular para essa figura feminina - que representa também uma visão da vida e do mundo dos humanos, e da hierarquia que os governa—rejeitada pela sociedade dos homens e que deseja se fazer conhecer, "as avessas' se necessário, pelo mal que lhes faz. A confusão de Lilith com Ísis, adorada como Grande Mãe que cura e salva, e com outros mitos vizinhos, de ambivalência benéfica-maléfica, faz-nos lembrar que seus efeitos sobre a vida humana dependem em grande parte da perspectiva em que os homens a inscrevem, e do olhar com que a encaram" (BRUNEL; PIERRE, 2000, p. 583/585).
} 
estar refletindo que sem um entendimento mais amplo a respeito da inserção da mulher e do que se espera dela, é muito difícil, segundo as autoras, compreender e tentar modificar a condição da submissão da enfermeira.

Em 1985 um outro artigo publicado por duas enfermeiras docentes da UnB (WRIGHT; CARNEIRO, 1985) busca também um resgate da história da mulher no sentido de entender a problemática da enfermeira especificamente no Brasil. Trata-se de um texto bastante interessante que avança em análise e interpretação do papel da mulher na sociedade e da mulher-enfermeira, apontando o viés da divisão social, técnica e sexual do trabalho que marca a profissão. Faz um mapeamento e resgate dos avanços mais importantes da enfermagem brasileira, insistindo que apesar dos ganhos a profissão ficou sempre subordinada ao poder médico, o que era de esperar porque conforme elas afirmam na conclusão:

...percebe-se que a sociedade ensinou a mulher a aceitar a autoridade masculina, e assim ela renuncia a criticar, a examinar, a julgar por conta própria mostrando, portanto um dos traços de seu caráter- a resignação. (...) $A$ simples justaposição do direito ao voto e o direito a uma profissão não constitui uma efetiva conquista de espaço da mulher na sociedade. Não se pode perder esses fatos de vista quando se relaciona o espaço ocupado pela mulher enfermeira, porque a situação mostra também que este não foi ditado por elas, mas pelas politicas de saúde, desde os primórdios até hoje e também pela divisão social do trabalho. (Ibid., p. 62).

O artigo tem o mérito de avançar na análise quando faz o desvelamento de uma realidade interpretada como natural pelo discurso hegemônico: entre as mulheres não há uma solidariedade orgânica no sentido de buscar seu espaço e direitos, uma vez que ainda é no espaço masculino que elas se inserem, o que vem determinando historicamente até mesmo a escolha profissional, muito mais no sentido do que era permitido às mulheres (magistério, enfermagem), enfim profissões consideradas femininas.

Ainda em 1985 em editorial intitulado "O Decênio 1975-1985 das Nações Unidas para a Mulher", a revista abre com comentários gerais sobre a Conferência em Nairóbi que contou com a participação de mais de 10.000 mulheres, comentários de técnicos da ONU com relação às questões relativas às mulheres e um breve relato do embate que se deu nos anos de 1951 a 1962 com o Ministério do Trabalho em cujo colegiado só homens tinham assento, para que o grupo de enfermeiros fosse enquadrado na Confederação Nacional de Profissionais Liberais, "em que todas as profissões de nivel superior enquadram seus órgãos". Aponta para a exclusão das mulheres da participação em decisões de cunho político e econômico e aponta a vantagem de se incrementar as pesquisas e divulgação dos obstáculos encontrados em profissões consideradas femininas.

Após três anos sem publicação sobre essa temática, Lopes (1988) publica o resumo de uma dissertação de mestrado apresentada ao curso de Sociologia da PUC/RS sob a forma de artigo científico. É o primeiro artigo que traz gênero como uma construção de identidade e aponta a perspectiva da dominação de gênero não se restringindo aos papéis sexuais. A autora é enfermeira e docente da Universidade do Rio Grande do Sul e aponta, efetivamente, como o próprio nome do trabalho diz, a vinculação entre a desvalorização histórica da mulher e as conseqüências para a enfermagem como profissão. Essa desvalorização está calcada no modelo patriarcal consolidado pelo modelo capitalista através da divisão sexual do trabalho, que reitera ideologicamente o caráter histórico das profissões "femininas", numa configuração do espaço público e do espaço privado, o primeiro masculino, articulado politicamente detentor de poder, o segundo feminino, desvalorizado e sem poder de articulação política. Essa conjuntura é crucial para a profissão conforme a própria autora afirma:

Enquanto profissão de nivel universitário a enfermagem engendrou uma composição socialmente aceitável para mulher: nem só privada nem só pública, é boa para a mulher, é bom para os filhos dessa mulher, essa é a argumentação. O caráter privado é transferido para o mundo público cristalizando-se nessas "profissões femininas", que reproduzem o caráter informal do poder da mulher. (lbid., p. 216).

No ano seguinte, (GASTALDO; MEYER, 1989) um outro artigo apresenta a mesma linha de pensamento, apreensão e crítica à profissão, no sentido de apresentar a história da enfermagem engendrada no contexto capitalista que reforça e mantém a divisão técnica, social e sexual do trabalho, e no caso da enfermagem a permanência da divisão entre trabalho intelectual e manual. O enfoque principal do texto como o próprio título sugere, é a ênfase na conduta ( aspecto moral no sentido de conduta acética e até mesmo assexuada, aparência física, postura pouco questionadora ) enfim, pouco investimento no conhecimento propriamente dito. As duas autoras são professoras universitárias e quando escreveram o artigo eram mestrandas do curso de pós graduação em educação da UFRGS. Apresento, aqui, o último parágrafo das considerações finais por entender o quanto ele é atual treze anos depois:

O desafio que se coloca para a enfermagem dos anos 90 e do próximo século é o da superação das contradições que nasceram com ela. A nivel da divisão social do trabalho, é preciso que a enfermeira, ao invés de controlar, alie-se às demais categorias da enfermagem, promovendo um entrelaçamento entre o fazer intelectual e manual. No que diz respeito a conduta $X$ conhecimento, ao invés de se discutir 'cor e integridade do esmalte', é necessário que se passe a discussão das questões da enfermagem enquanto profissão feminina, com todos os ônus que isso acarreta. As escolas de enfermagem só formarão profissionais realmente aptos a avançar na enfermagem, quando permitirem que as contradições existentes na profissão aflorem e sejam tratadas ao longo do processo de formação da enfermeira. (Ibid., p. 12-13).

O trabalho que inaugura a década de noventa tratando a questão da enfermagem enquanto profissão feminina é baseado na Tese de Livre Docência da autora, professora da Escola de Enfermagem Anna Nery da UFRJ. (PADILHA, 1991). No resumo a autora já deixa claro que trabalha com estereótipos sexistas que se evidenciam no ambiente familiar, pela divisão de tarefas, pátrio poder, enfim condições familiares que acabam por condicionar a escolha profissional. Aponta pistas no sentido de que o papel social de subordinação da mulher reflete na mulher-enfermeira, cujo 
comportamento profissional na maior parte das vezes se faz sem questionamentos, refletindo o padrão determinado e aceito, socialmente, como feminino.

Em 1993 na seção intitulada documentos encontrase um artigo informativo (COSTA; SARDENBERG, 1993) que traz a relação de todos os núcleos ligados à rede nortenordeste de estudos sobre a mulher e relações de gênero. As autoras são professoras da UFBA, a primeira do departamento de ciência política, a segunda do departamento de antropologia, ambas ligadas à coordenação de núcleos de estudo sobre a mulher em sua universidade.

Nesse mesmo ano um trabalho de Lunardi (1993) já sinaliza e utiliza a categoria gênero explicitado já no título do artigo escrito pela enfermeira e professora do curso de graduação em enfermagem da Universidade do Rio Grande, à época mestranda em educação da FACED-UFRGS. Através de uma contextualização histórica da enfermagem aborda a questão disciplinar a partir do conceito de poder de Foucalt. A meu ver avança na discussão das relações de gênero enquanto categoria socialmente construída independente do sexo quando diz que:

As professoras enfermeiras, à semelhança de Nightingale, descritas como extremamente repressoras, ao agirem de modo autoritário, dominante e exigente em relação às alunas, parecem também nessas relações, ter declinado de um polo feminino, optando por um papel masculino, mais poderoso e dominador, num paradigma patriarcal e numa visão de mundo essencialmente masculina, enquanto processo disciplinador. (Ibid., p. 294).

O primeiro número da revista em 1995, traz um artigo de Godoy (1995) bastante interessante na medida em que afirma que efetivamente as relações de gênero no processo de educação muitas vezes exclui a mulher por manter certos estereótipos aceitáveis do feminino. Mas contribui profundamente ao dizer que os estudos de gênero devem ser incorporados ao ensino da enfermagem, conforme palavras da autora:

Ocorre que enquanto nas Ciências Sociais, apesar de não hegemônico, esse enfoque tem sido corrente, na área da saúde ele é ainda praticamente desconhecido. Este desconhecimento leva a que seja estigmatizado e alvo de preconceitos. Assim como a História, as Ciências Biológicas - e as práticas sociais que delas resultam são androcêntricas. Se na sociedade em geral, o poder é adulto, masculino, branco e rico, no caso da saúde ele é adulto, masculino, branco, rico e médico. Romper com essa dominação significa reconhecer não só a importância social da mulher, como a das demais práticas que compõem a assistência à saúde coletiva, além da prática médica, entre elas, a da enfermagem.( grifos meus). (Ibid., p. 57-8).

A Revista Brasileira de Enfermagem (1995) brindanos com um belíssimo editorial falando da IV Conferência Mundial da ONU sobre a mulher, que aconteceria, em setembro, na China, além de fazer uma breve retrospectiva dos movimentos importantes que aconteceram na metade dessa década em que a participação dos movimentos de mulheres foram fundamentais. É particularmente gratificante nesse editorial o questionamento sobre até que ponto o posicionamento das enfermeiras não tem reforçado enquanto agentes "de processos discriminatórios e do discurso e práticas medicalizadoras sobre o corpo da mulher"; do não compromisso com situações em que estão inseridas de forma desigual as mulheres e, especificamente no setor saúde a não implantação e consolidação do PAISM. Finaliza o editorial revendo o que a gestão da $A B E n$ avançou no sentido de "estabelecer uma relação mais orgânica com os movimentos de mulheres "inclusive com o tema da 56a Semana Brasileira de Enfermagem "Mulher- o Ser e o Fazer na Saúde".

Um artigo publicado em 1997 (PAIVA, 1997), apresentado no $9^{\circ}$ SENPE do mesmo ano em Vitória trás uma contribuição no sentido de apresentar as perspectivas da Teoria Feminista de uma maneira mais abrangente, como paradigma que possa vir a estabelecer novas relações entre seres humanos de maneira mais igualitária. Não traz o assunto nesse artigo especificamente para a enfermagem mas a meu ver sinaliza novas possibilidades epistemológicas e metodológicas para a pesquisa em enfermagem.

Em 1998, um outro artigo originariamente trabalho apresentado no VII Congresso Brasileiro de Sociologia realizado em agosto de 1997 na UnB, volta a tratar com muita propriedade a problemática das relações de gênero $e$ suas articulações com a enfermagem. As autoras são professoras, a primeira do departamento de sociologia da UNB e a segunda da UNIFESP. A significativa contribuição desse documento para os estudos de gênero relacionados à profissão de enfermagem traduz-se, especialmente, no último parágrafo do texto em que as autoras afirmam:

O cuidado na perspectiva relacional opera dialeticamente no processo saúde-doença, e incorpora a subjetividade, a afetividade, a palavra, os gestos corporais, o ato de tocar, a percepção para além da técnica. Este é a nosso ver o grande desafio com o qual as/os profissionais de enfermagem têm que se defrontar, para a construção de sua identidade profissional do seu objeto de conhecimento enquanto uma prática social de sexo e gênero. (BANDEIRA; OLIVEIRA, 1998, p. 693)

\section{O DESPERTAR DE LILITH}

Como considerações finais deste estudo passo a pontuar algumas questões que se tornaram bastante transparentes, e que, a meu ver, serão fundamentais para o despertar de Lilith, da enfermagem no feminino- entendido feminino aqui não como essência do eterno feminino, mas como construção social de gênero-enquanto profissão histórica e socialmente construída.

A primeira questão insere-se no fato de que a maioria das autoras estão vinculadas ao ensino e, provavelmente, é esse espaço que articulado ao tecido real onde se desenvolvem as práticas de saúde de maneira geral e as de enfermagem em especial, poderão efetivamente trazer Lilith em igualdade de condições, - como Adão criada a partir do barro-,tornar mais horizontalizadas as relações de poder a partir da desnaturalização dos conceitos de masculino e feminino como diferença apenas sexual e que engendram as desigualdades de poder entre homens e mulheres. $O$ ensino de enfermagem precisa incorporar os estudos de gênero de maneira crítica desvelando as implicações que até hoje marcam a profissão ainda vista como feminina, 
performatizada em muitos casos a partir dos estereótipos que permanecem vivos na profissão, cindida pela permanente divisão social do trabalho.

Importante, também, que permaneçam abertas as "portas e janelas" que periódicos como a REBEn abrem para além do eminentemente técnico na profissão. Se num primeiro e descuidado olhar parece uma inserção tímida da revista na publicação de artigos que remetam à problemática da condição social da mulher e, principalmente, das relações de gênero, a um olhar mais atento percebe-se que a contribuição é enorme do ponto de vista da qualidade dos textos apresentados, e como esses artigos evidenciam o caminhar da enfermagem dentro de um contexto mais amplo.

Os editoriais que se dedicaram aos dois grandes encontros internacionais de mulheres nas décadas estudadas é uma prova viva de que a REBEn enquanto meio de divulgação e de atualização de uma categoria profissional não esteve alienada quanto à nossa condição de mulherenfermeira. Foi muito prazeroso avançar nesse desvelamento que demarca inclusive a minha trajetória profissional, e o meu "lado Lilith": a identificação com um dos primeiros artigos ${ }^{13}$ marcado pela indignação jovem, em contraponto 'a maturidade do último artigo referenciado ${ }^{14} \mathrm{em}$ que as dimensões do cuidado ultrapassam de certa maneira o discurso do científico, para se inserir num contexto maior em que também as dimensões da vida se ampliam.

Despertar Lilith significa manter-se jovem aos 70 anos, o que a REBEn tem demonstrado sempre, possibilitando o mergulho no futuro de maneira menos preconceituosa, mais humana, mais questionadora e reivindicadora do nosso lugar não acima, mas ao lado dos seres humanos do gênero masculino. O nascimento de Lilith nesse milênio depende muito mais do nosso olhar e da inscrição como mulheres e homens fazemos dela, e menos da perspectiva em que apenas os homens a olham e a inscrevem...

\section{REFERÊNCIAS BIBLIOGRÁFICAS}

BANDEIRA, L. ; Oliveira, E. M. de. Representações de gênero e moralidade na prática profissional da Enfermagem. Rev. Bras. Enferm., Brasília, v. 51, n. 4, p. 677-696, out./ dez.1998.

BRUNEL, P. Dicionário de mitos literários. 3.ed. Rio de Janeiro: José Olympio, 2000.
CASTRO, I. B. e.; CARVALHO, V. de. ; BORGES, M. V. Reflexões sobre a prática de Enfermagem no Brasil e na América Latina- implicações educacionais. Rev. Bras. Enferm., Brasilia, v.35, n.3/4, p.185-191, jul./dez. 1982.

CORADINI, S. R.; BARBIANI, R. A profissional enfermeira frente às influências da evolução histórica da mulher. Rev. Bras. Enferm., Brasília, v.36, p. 246-254, jul./dez. 1983.

COSTA, A. A. A. ; SARDENBERG, C. M. B. Rede Regional Norte Nordeste de Estudos e Pesquisas sobre a Mulher e Relações de Gênero. Rev. Bras. Enferm., Brasília, v.46, n. 2, 171-175, abr./jun. 1993.

GASTALDO, D. M. ; MEYER, D. E. A formação da enfermeira: ênfase na conduta em detrimento do conhecimento. Rev. Bras. Enferm., Brasília, v.42, n. 1, 2, 3/4, p.7-13, jan/ dez.1989.

GODOY, R. M. A educação e o processo de inclusãoexclusão social da mulher: uma questão de gênero? Rev. Bras. Enferm., Brasilia, v.48, n.1, p.51-59, jan./mar.1995.

\section{GROSSI, M. P. Feministas históricas e novas feministas} no Brasil. Florianópolis: UFSC, s/d.

LOPES, M. J. L. Trabalho da enfermeira: nem público, nem privado feminino doméstico e desvalorizado. Rev. Bras. Enferm., Brasilia, v.41, n.3/4, p.211-217, jul./dez. 1988.

LUNARDI, V. L. Relacionando enfermagem, gênero e formação disciplinar. Rev. Bras. Enferm., Brasilia, v.46, n. 3/4, 286-295, jul./dez.1993.

PADILHA, M. I. C. de S. O Resgate das raizes- a influência da formação familiar e social na escolha e exercício da enfermagem. Rev. Bras. Enferm., Brasilia, v. 44, n.1, p. 3035, jan./mar. 1991.

PAIVA, M. S. Teoria feminista: o desafio de tornar-se um paradigma. Rev. Bras. Enferm., Brasília, v.50, n.4, p.517524, out./dez. 1997.

REVISTA BRASILEIRA DE ENFERMAGEM. Editorial. Rev. Bras. Enferm., Brasilia, v.48, n.2, p.107-108, abr./ jun. 1995.

WRIGHT, M. da G. M.; CARNEIRO, A. O espaço da mulher brasileira e o espaço da enfermeira brasileira. Rev. Bras. Enferm., Brasilia, v. 38, n.1, p.55-62, jan./mar. 1985. 